\title{
ОСОБЕННОСТИ РАЗВИТИЯ МЛАДШИХ ШКОЛЬНИКОВ С НАРУШЕНИЕМ ИНТЕЛЛЕКТА, ОБУЧАЮЩИХСЯ ПО СПЕЦИАЛЬНОЙ ИНДИВИДУАЛЬНОЙ ПРОГРАММЕ РАЗВИТИЯ
}

\section{DEVELOPMENT FEATURES \\ OF YOUNGER PUPILS WITH \\ INTELLECTUAL DISABILITIES \\ TRAINING ON A SPECIAL INDIVIDUAL DEVELOPMENT PROGRAM}

\section{Abramova \\ M. Tanyushkina}

Summary: This article is devoted to the study of the level of cognitive and communicative development of children studying according to a special individual development program and in need of tutor support. The role of a tutor in the development and implementation of a special individual development program for a student with intellectual disabilities is also indicated.

Keywords: junior schoolchildren, intellectual disabilities, tutoring.

\author{
Абрамова Инна Викторовна \\ К.п.н., доцент, Мордовский государственный \\ педагогический университет имени М.Е. Евсевьева (г. \\ (аранск) \\ iva-76@yandex.ru \\ Танюшкина Мария Евгеньевна \\ Мордовский государственный педагогический \\ университет имени М.Е. Евсевьева (2. Саранск) \\ mariya.maksimenkova@mail.ru \\ Тиньгаева Ксения Сергеевна \\ Мордовский государственный педагогический \\ университет имени М.Е. Евсевьева (2. Саранск) \\ k-tingaeva@mail.ru
}

Аннотация: Настоящая статья посвящена исследованию уровня познавательного и коммуникативного развития детей, обучающихся по специальной индивидуальной программе развития и нуждающихся в тьюторском сопровождении. Также обозначена роль тьютора в разработке и реализации специальной индивидуальной программы развития обучающегося с нарушением интеллекта.

Ключевые слова: младшие школьники, нарушение интеллекта, тьюторское сопровождение.

С.В. Алехина, Т.М. Ковалева, Е.В. Кузьмина и т.д. [8; 10; 12].

Вопросам тьюторского сопровождения, интерпретации тьюторства в инклюзивной практике посвящено большое количество исследований, например, работы И.В. Абрамовой, С.В. Алещенко, Е.А. Вишняковой и т.д. $[1 ; 11 ; 3]$.

По мнению указанных авторов тьютор является исторически сформировавшейся особенной педагогической позицией, которая гарантирует разработку личных образовательных программ обучающихся и сопровождает процедуру персонального образования в образовательной организации [4].

Е.А. Вишнякова позицию тьютора определяет как эксперта, исполняющего прямое сопровождение детей (ребенка) с ограниченными возможностями здоровья в течение всего учебного времени, включая фронтальные и индивидуальные занятия, а также перемены и другие режимные моменты [3].

Также можно до бесконечности перечислять то, как определяют понятие тьютор многие исследователи. 
Тьютор это: наставник, помощник; преподаватель; консультант; посредник; человек, который научит самостоятельно решать проблемы; позиция, сопровождающая, поддерживающая процесс самообразования, индивидуальный образовательный поиск и т.д.

С понятием «тьютор» тесно связано «тьюторское сопровождение». Тьюторское сопровождение определяют как особый тип сопровождения образовательной деятельности человека в ситуациях неопределенности выбора и перехода по этапам развития, в процессе которого обучающийся выполняет образовательные действия, а тьютор создает условия для их осуществления и осмысления (Е.А. Суханова, А.Г. Чернявская) [10].

Ряд авторов считает, что тьюторское сопровождение - это педагогическая деятельность по индивидуализации образования, направленная на выявление и развитие образовательных мотивов и интересов обучающегося, поиск образовательных ресурсов для создания индивидуальной образовательной программы [4].

Перейдем к подтверждению фактов изложеных в статье. На базе ГБОУ РМ «Саранская общеобразовательная школа для детей с ограниченными возможностями здоровья» г.о. Саранск, было проведено исследование, с младшими школьниками с нарушением интеллекта, обучающимися по специальной индивидуальной программе развития. Данное экспериментальное исследование включало в себя два направления. Для начала изучался опыт деятельности тьютора в работе с такими детьми, затем проводилось исследование непосредственно детей.

Для изучения опыта деятельности тьютора в данной организации была проведена беседа и анкета с тьюторами. Результаты анкетирования и бесед показали, что на данный момент профессия тьютора и собственно тьюторское сопровождение детей с интеллектуальными нарушениями только набирает обороты, и в связи с этим самим тьюторам тяжело приспособиться к изменениям происходящим в образовании. Тьюторы испытывают трудности в организации материально-технических условий, особо важных при реализации обучения младших школьников с интеллектуальными нарушениями обучающихся по специальной индивидуальной программе развития. Не достаточно опыта работы с данной категорией детей, неподготовленность педагогов в решен ии тех или иных вопросов, нехватка методического и дидактического материала. Беседа подтвердила тот факт, что младшим школьникам с нарушением интеллекта, обучающимся по специальной индивидуальной программе развития действительно требуется помощь тьютор а.

Следующим направлением в нашем эксперименте явилось исследование младших школьников с нарушением интеллекта. В диагностике детей мы придерживались двух аспектов: познавательное развитие и коммуникативное развитие. За осн ову исследования были взяты пособия С.Д. Забрамной, М.А. Москвиной [8].

Эксперимент проводился индивидуальн о с каждым из обучающихся. В начале с детьми проводилась беседа для установления контакта и настроя н а положительную работу. Далее с помощью диагностических методик осуществлялось исследование уровня сформированности познавательных процессов. Если ребенок уставал, ему разрешалось сделать физкультминутку, гимнастику, для отдыха и приступить к выполнению заданий снова. Также перед началом работы за компьютером обязательно проводилась гимнастика для глаз.

Представим результаты, полученные с помощью методик, направленных на изучение сформированности познавательных процессов.

Полученные данные при исследовании логичности и гибкости мышления по методике «Простые аналогии» таковы: у всех детей (100\%) низкий уровень логичности и гибкости мышления, что говорит о том, что дети давали менее 5 правильных ответов.

Далее проводилось изучение сформированности понятийной сферы испытуемых, способности к классификации и анализу по методикам «Исключение понятий» и «Выделение двух существенных признаков». Анализ результатов показал, что у детей также низкий уровень, т. е обобщить родовым понятием они смогли только 2-3 ряда и дали 3-5 правильных ответов.

Для изучения степени сформированности у детей с нарушением интеллекта целостных образов объектов и предметов окружающего мира была использована методика «Разрезные картинки». Из полученных данных делаем вывод о том, что у детей данный показатель находится на низком, и очень низком уровнях. Обучающиеся не осознавали цели задания, работали неадекватно в условиях обучения выполняли работу хаотически, после обучения не переходили к самостоятельному выполнению.

Для установления способности ребенка понять целостность сюжета, умение определять причинно-следственные связи, составлять связный рассказ, нами была применена методика «Последовательные картинки». При работе над данным заданием дети не соблюдали последовательность, не замечали ошибок и их рассказ представлял собой описание отдельных элементов картинок, что подтверждает низкий уровень познавательного и коммуникативного развития. 
Для исследования объема кратковременной слуховой памяти и определение объема зрительного непроизвольного запоминания были использованы методики «Запомни десять слов» и «Зрительная непроизвольная память». Из анализа результатов первой методики делаем вывод о том, что у всех детей низкий объем кратковременной слуховой памяти, так как они запомнили и воспроизвели менее трех слов. Исходя из результатов второй методики, определяем, что 33 \% детей можно отнести к пятому уровню, что говорит о низкой способности к непроизвольному запоминанию и $67 \%$ детей относятся к четвертому уровню, что отражает недостаточный объем непроизвольной зрительной памяти.

В ходе проведения методик дети были активны, заинтересованы заданием, но, к сожалению, показали низкие результаты.

Что бы оценить объем внимания детей, нами была проведена методика «Запомни и расставь точки». Из результатов делаем вывод о том, что 1 ребенок (33 \%) показал низкие результаты. На протяжении проведения методики правильно смог воспроизвести 2 точки. 2 ребенка (67\%) показали очень низкие результаты и смогли правильно воспроизвести менее одной точки.

Для исследования способности к обобщению у младших школьников с нарушением интеллекта был использован Тест «Что лишнее?» По результатам диагностики было установлено, что большинство обучающихся допустили от 7 до 12 ошибок (61,1\%), не значительная часть детей допустили от 13 до 17 ошибок (39,9 \%). Следовательно, можно сделать вывод о том, что внимание неустойчивое и уровень его концентрации низкий.

Для диагностики избирательности и концентрации внимания нами была выбрана Методика: «Тест Мюнстерберга». По результатам было установлено, что большинство младших школьников затратили на выполнение задания от 200 до 220 сек., что соответствует низкому уровню избирательности внимания.

Для оценки состояния слуховой памяти нами использована Методика А.Р. Лурия «10 слов». Результаты получились следующие: средний уровень выявлен у двух человек и низкий уровень у одного обучающегося с интеллектуальными нарушениями.

После того, как исследовали познавательную сферу, мы приступили к исследованию коммуникативных навыков. Для этого использовали методику «Понимание сюжетных изображений», целью которой являлось:установление осознания ребенком смысла ситуации, выявление пространственно-временных и причинно-следственных отношений. Анализируя результаты, полученные в ходе проведения данной методики, обучающиеся были отнесены к третьему уровню. На данном уровне обучающиеся в состоянии понять простую сюжетную картинку. Они могут ответить на вопросы по картинке, но составление связного рассказа для них недоступно. Трудности возникают в процессе осознания скрытого смысла текста, детям недоступно установление последовательности событий. Рассказ короток, прост. Выявляется отсутствие навыка составления рассказа, небогатая речь.

Также применялась методика «Понимание скрытого смысла текста». Её целью явилось определение степени понимания ребенком очевидного и скрытого смысла короткого рассказа, а также способность воспроизвести его в определенной последовательности с необходимыми подробностями. На основании полученных результатов также относим детей к третьему уровню, так как они способны пересказать несложные тексты, застревают на деталях, не понимают общий смысл рассказа, им требуется помощь в объяснении смысла.

Представим обобщенные результаты, полученные в ходе проведения исследования в виде таблицы.

Таблица 1

Результаты проведения исследования

\begin{tabular}{|c|c|c|}
\hline \multirow{2}{*}{ Уровень развития } & \multicolumn{2}{|c|}{ Количество испытуемых } \\
\cline { 2 - 3 } & абс. & $\%$ \\
\hline высокий & 0 & 0 \\
\hline средний & 0 & 0 \\
\hline низкий & 2 & $67 \%$ \\
\hline очень низкий & 1 & $33 \%$ \\
\hline
\end{tabular}

Из всего вышеперечисленного делаем вывод о том, что уровень познавательного развития детей, также как и уровень коммуникативных навыков находится низком и очень низком уровне.

Полученные данные подтверждают необходимость проведения занятий, направленных на развитие интеллектуальных способностей, в рамках тьюторского сопровождения. Также полученные данные подтвердили необходимость обучения детей с нарушением интеллекта по специальной индивидуальной программе развития. В связи с чем необходима тщательная организация коррекционно-образовательного процесса при обязательном тьюторском сопровождении для обучающихся, имеющих тяжелые формы патологии развития. Для более результативной коррекционной работы, нами была разработана программа тьюторского сопровождения младших школьников с нарушением интеллекта в условиях реализации специальной программы развития, эффективность которой предстоит проверить. 


\section{ЛИТЕРАТУРА}

1. Абрамова И.В. Подготовка студентов педагогического вуза к тьюторскому сопровождению детей в условиях инклюзивной практики / И.В. Абрамова, Н.В. Рябова // Гуманитарные науки и образование. - 2016. - № 4 (28). - С. 51-55.

2. Белякова И.В. Психология умственно отсталого школьника: учебное пособие / И.В. Белякова, В.Г. Петрова. - М.: Академия, 2002. - 160 с.

3. Вишнякова Е.А. Методические рекомендации с моделями тьюторского сопровождения по обучению детей с ОВЗ / Е.А. Вишнякова. - Липецк: ГАУДПо ЛО «ИР0», 2017. $-66 \mathrm{c}$.

4. Есина С.А Методические рекомендации по разработке специальной индивидуальной программы развития (СИПР) / С.А. Есина, Н.А. Чиркунова. - Красноярск: Красноярский государственный педагогический университет им. В.П. Астафьева, 2016. - 30 с.

5. Забрамная С.Д. Психолого-педагогическая диагностика умственного развития детей: учебник для студентов дефектологических факультетов педвузов и университетов. - М.: Просвещение: Владос, 1995. - 112 с.

6. Зарубина Н.В. Реализация СИПРа в соответствии с ФГОС образования обучающихся с умственной отсталостью (интеллектуальными нарушениями) / Н.В. Зарубина // Интегративные тенденции в медицине и образовании. - 2017. -Т. 1. - №2. - С. - 36-40.

7. Левченко И.Ю. Психологическое изучение детей с нарушениями развития / И.Ю. Левченко, Н.А. Киселева. - М.: Национальный книжный центр, 2016. $160 \mathrm{c}$.

8. Организация инклюзивного образования для детей с ограниченными возможностями здоровья : учебное пособие / отв. ред. С.В. Алехина, Е.Н. Кутепова. - М.: МГППУ, 2013. -324 с.

9. Приказ Министерства образования и науки Российской Федерации от 19.12.2014 № 1598 «0б утверждении федерального государственного образовательного стандарта начального общего образования обучающихся с ограниченными возможностями здоровья» [Электронный ресурс] // Система Гарант. - 2018. - URL: http://www.garant.ru/products/ipo/prime/doc/70762366/.

10. Профессия «тьютор» / Т.М. Ковалева, Е.И. Кобыща, С.Ю. Попова (Смолик), А.А. Теров, М.Ю. Чередилина. - М.: «СФК-офис», 2012. - 246 с.

11. Тьюторское сопровождение детей с ОВЗ: методические рекомендации для тьюторов, педагогов, специалистов образовательных учреждений / сост. С.В. Алещенко. - Томск, 2014. -42 с

12. Тьюторское сопровождение детей с ограниченными возможностями здоровья в образовательных учреждениях, реализующих инклюзивную практику: метод. рекомендации / Сост. Е.В. Кузьмина. - М.: МГППУ, 2012. - 57 с.

(c) Абрамова Инна Викторовна (iva-76@yandex.ru), Танюшкина Мария Евгеньевна (mariya.maksimenkova@mail.ru),



